\title{
Considering Core Competencies: Social and Emotional Learning in British Columbia's Redesigned Curriculum
}

\author{
Meaghan Storey \\ University of Victoria \\ mmostorey@uvic.ca
}

\begin{abstract}
The development of the redesigned $\mathrm{BC}$ curriculum marks a shift to a more integrated holistic approach to learning that includes focused attention on social and emotional learning (SEL). This article examines the development of the redesigned $\mathrm{BC}$ curriculum through the lens of SEL identifying challenges encountered and strengths upon which to build. Available materials, reports, and informing documents used in the planning, consultation, and development process are examined to establish an overview of the rationale, objectives, theoretical foundations, and intentions of the redesigned curriculum with respect to SEL. Investigation revealed considerable early emphasis on SEL, particularly through the Core Competencies envisioned as a reorientation towards skillsbased, $21^{\text {st }}$ century learning. However, a recent return to content-focused language in both planning and assessment are noted. Implications and directions for future research are suggested.
\end{abstract}

\section{Introduction}

"If we teach today's students as we taught yesterday's, we rob them of tomorrow." John Dewey

The importance of social and emotional learning (SEL) to students' academic and life success is now well established in education and psychology research (Collaborative for Academic Social and Emotional Learning, 2015; Durlak, Weissberg, Dymicki, Taylor, \& Schellinger, 2011; Elias, Zins, Graczyk, \& Weissberg, 2003). For almost 20 years in British Columbia, education policy has evolved with an increasing awareness of emerging SEL scholarship. The development of the redesigned BC curriculum marks a shift to a more integrated holistic approach to learning that includes focused attention on the social and emotional development of learners. The intentional incorporation of current SEL research and practice heralds an acceptance of SEL as fundamental to the success of $21^{\text {st }}$ century learners and marks the new BC curriculum as ambitious, progressive, and unprecedented.

To support educators, learners, and families and to achieve a true culture-shift it is important to examine the changing role of SEL as the BC Ministry of Education moves

Journal of Contemporary Issues in Education, 2017, 12(2), pp.34-49. 
forward with widespread implementation ${ }^{1}$ (British Columbia Ministry of Education, $2015 b, 2017 \mathrm{c})$. This article seeks to bridge a gap in the literature by engaging in reflection and analysis of the development of the redesigned $\mathrm{BC}$ curriculum through an SEL lens. Available materials, reports, and informing documents used in the planning, consultation, and development process are examined to establish an overview of the rationale, objectives, theoretical foundations and intentions of the new curriculum with respect to SEL. This article also examines the evolution of the role of SEL over time to gauge alignment between policy and practice identifying challenges encountered and strengths upon which to build.

\section{Social and Emotional Learning}

Social and emotional competence is described as:

...the ability to understand, manage, and express the social and emotional aspects of one's life in ways that enable the successful management of life tasks such as learning, forming relationships, solving everyday problems, and adapting to the complex demands of growth and development. (Elias et al., 1997, p. 2)

Social and emotional learning continues to gain prominence as an essential component of the school curriculum, sometimes referred to as the "missing piece" in education (Bridgeland, Bruce, \& Hariharan, 2013). However, critics have highlighted the limited potential of social and emotional learning programs, particularly with respect to isolated programming targeting elementary age students.

For the purposes of this analysis, guidance will be taken from the Collaborative for Academic, Social, and Emotional Learning (CASEL), current leaders in SEL research. To support educational programming, CASEL distilled the range of intra- and interpersonal skills to five competencies. To paraphrase CASEL's five core areas:

- Self-awareness is recognizing our thoughts and emotions and their impact on our behaviour, developing confidence and optimism, and understanding our strengths and limitations.

- Self-management includes emotional, mental, and behavioural self-regulation, stress management, impulse control, self-motivation, and pursuing personal and academic goals.

- Social awareness includes understanding social and ethical behavioural norms, empathizing with and considering perspectives of diverse groups, and identifying resources and supports in one's life.

- Relationship skills use communication and interpersonal skills to create and maintain healthy, rewarding relationships with a variety of people and navigate conflict and social pressure.

- Responsible decision-making means making constructive and respectful social and behavioural choices considering ethics, safety, norms, and consequences for

\footnotetext{
${ }^{1}$ While the K-9 curriculum is being fully implemented, the grade 10-12 graduation years curriculum is still currently in draft form and is expected to be implemented province-wide in 2018-2019 (British Columbia Ministry of Education, 2017c).

Journal of Contemporary Issues in Education, 2017, 12(2), pp. 34-49.

ISSN 1718-4770 @ 2017 University of Alberta/Centre for Global Citizenship Education and Research 
self and others. (Collaborative for Academic Social and Emotional Learning, 2016)

These definitions, together with additional articulations in the literature, will be used as the basis for comparison and examination of the explicit and implicit inclusion of these competencies in the new curriculum.

\section{Origins: Educated Citizen, Social Responsibility, and $21^{\text {st }}$ Century Skills}

The genesis of SEL inclusion in the recent efforts to reform the BC curriculum can be traced to an 1989 Order-in-Council under Section 169 (3) of the School Act entitled "Mandate for the School System Province of British Columbia" (Brummet, 2013). This Order established policy direction for the BC school system and outlined the parameters for development. Evidence of the importance of social and emotional development to learning, life, and society can be discerned in the document's goals and definitions. Specifically, the legislation established the definition of a "quality" education as one that "assists in the development of human potential and improves the well being of each individual person in British Columbia society" (p. D-88). The mandate tasks schools with fostering "The Educated Citizen," providing a guiding definition that contains a number of characteristics that correspond to the delineated CASEL competencies (p. D88). The Educated Citizen exhibits skills in critical thinking, communication, creativity, decision making, and advocacy, they are self-motivated, cooperative, principled, responsible, respectful of others regardless of differences, contribute to society and has positive self-image, finding satisfaction in achievement and physical well being (p. D88). Further, the mandate charges schools with helping students develop

.... a sense of self-worth and personal initiative; to develop an appreciation of the fine arts and an understanding of cultural heritage; to develop an understanding of the importance of physical health and well being; to develop a sense of social responsibility, and a tolerance and respect for the ideas and beliefs of others. (p. D-89)

This is a clear indication of the value placed on the development of students beyond the acquisition of academic knowledge and an intention to actively support social and emotional development in the school system.

A further step towards integrated SEL occurred in 2000 with the Ministry of Education's first inclusion of social responsibility among the provincial performance standards alongside reading, writing, and numeracy (British Columbia Ministry of Education, 2001). Also rooted in the 1989 mandate, this addition signifies an important shift in the onus on educational institutions to actively facilitate societal advancement through individual development on a level equal to literacy and numeracy skills. A review of the Social Responsibility Framework reveals considerable alignment with SEL skills. It incorporates conflict resolution, respectful communication, perspective-taking, responsibility, defending human rights, and working towards a better future as contributing members of the school and classroom community (p. 4).

In addition to the government mandate and vision of the Educated Citizen, this shift is also motivated by the essential need for post-secondary skills. In the Parent's Guide to the new curriculum (British Columbia Ministry of Education, 2016a), the Journal of Contemporary Issues in Education, 2017, 12(2), pp. 34-49. 
Ministry points to research on $21^{\text {st }}$ century learning skills and employability emphasizing adaptability, critical and creative thinking, communication and social skills (see Ananiadou \& Claro, 2009; National Education Association, 2010; National Research Council, 2012; Partnership for 21st Century Learning, 2009). Overlap in all of these areas is evident in SEL theory and in the development of essential components of the new BC curriculum.

\section{Evolution of the Core Competencies}

At the outset of the formal re-design process the Ministry established the Curriculum and Assessment Framework Advisory Group ("The Advisory Group") in 2011 to advise on the new direction (British Columbia Ministry of Education, 2012, p. 3). The Advisory Group's first report "Enabling Innovation" outlines their initial recommendations as well as feedback from consultations with 12 regional groups. The first iteration of the current Core Competencies appear in this discussion (British Columbia Ministry of Education, 2012). Then designated "Cross-Curricular Competencies," these provide the most explicit inclusion of SEL in the redesign. Currently comprised of Communication, Critical Thinking, Creative Thinking, Positive Personal and Cultural Identity, Personal Awareness and Responsibility, and Social Responsibility, an examination of the evolution, application, and value of these competencies allows insight into the intentions of the committee and the Ministry.

In their first discussion paper, the Advisory Group outlined the working definitions of the five "Cross-Curricular Competencies" which generally align with the current definitions with some changes and elaborations:

- Communication is the imparting or exchange of information, experiences, and ideas through language, symbols, movement, or images to build a common understanding.

- Critical Thinking is focused on deciding what is reasonable to believe or do in a given situation.

- Creative Thinking and Innovation is the process of generating and implementing new ideas.

- Personal Responsibility and Well-being is taking responsibility for one's actions, being self-regulating, making ethical decisions in complex situations, accepting consequences, and understanding how one's actions affect others. Among other things, this competency includes financial literacy.

- Social Responsibility is being able to consider the perspective of and empathize with others, to recognize and appreciate diversity, to defend human rights, to solve problems in peaceful ways, and to contribute towards social, cultural, and ecological causes. Notably, collaboration is also within the purview of this competency. (p. 5)

The Advisory Group explicitly stated their intention to "encompass both cognitive learning (communication, critical thinking, creative thinking and innovation) and social and emotional learning (personal responsibility and well-being, social responsibility)" ( $p$. 5). While the Ministry then employed this bifurcation, a review of current research in the field suggests that all of these areas would now be classified under the umbrella of SEL 
encompassing both cognitive and affective domains of development (see CASEL, 2015, 2016; Winans, 2012; Zins \& Elias, 2006).

The Advisory Group also established parameters for the future development and application of the competencies including that they be clearly defined for both curriculum and assessment purposes. They also specified that these definitions should be "supported with descriptive continua and student samples, similar to performance standards, to describe and illustrate the developmental stages of each competency" and "clearly related to complex real-world tasks and performances" (British Columbia Ministry of Education, 2012, p. 5). Further, the importance of establishing "competency links" was emphasized in order to connect Core Competencies directly with each area of learning (p. 6). These guidelines support the Ministry's intention for integrative design across subjects and also the intention to provide valuable practical support for teachers in understanding, developing and addressing these competencies in a meaningful way.

This early planning document also contained a clear objective for some form of assessment of these competencies. The Advisory Group "recommended that teachers report at key times in the year on Cross-Curricular Competencies and key concepts within areas of learning using clear performance based language" (p. 7). Identifying the complications with traditional marking schemes, an emphasis was placed on selfassessment and flexibility in demonstrating competency (p. 7).

Twelve regional working groups of 30-150 stakeholders including parents, students, teachers, faculties of education, and aboriginal groups provided feedback on these ideas. The consultations revealed "strong support for addressing competencies in curriculum, assessment, reporting, and graduation" (p. 9). In fact, the regional groups explored a competency-centered model with many participants stating that graduation should be based on a demonstration of competencies rather than course credit and that a competency-based exit assessment should be required to graduate (p. 9). Again, concerns with traditional grading were noted, but overall "Across all regional sessions there was little question about the five competencies presented" and the proposed categories "were validated as the essential Cross-Curricular Competencies" (p.8). Later in this analysis curricular integration, practical support for teachers transitioning to the new system, as well as concerns about assessment become continuing challenges for program planners will be discussed in greater depth.

\section{A Framework for Competency Development}

Following the consultation process, the Ministry undertook the next step establishing a framework for competency development including gathering research, creating a rationale that defines each competency, and developing continua and samples in collaboration with teachers and assessment experts. With respect to research, the initial Advisory Group report pointed to a list of resources on the Ministry website (p. 3). This list is referenced by many other reports related to the redesign process and includes a lengthy collection of resources on all aspects of curriculum development (British Columbia Ministry of Education, 2013a, 2015c). It does not make specific reference to when the resources were consulted or employed in the process.

An examination of the 95 resources included on the list revealed few that specifically address SEL beyond the domains of critical and creative thinking. The main

Journal of Contemporary Issues in Education, 2017, 12(2), pp. 34-49. 
SEL resource is a technical report written for the Ministry of Education by Dr. SchonertReichl, a prominent SEL researcher at the University of British Columbia (UBC) (Schonert-Reichl, 2012). The June 2012 report focused on two of the proposed CrossCurricular Competencies: Personal Responsibility and Well-Being and Social Responsibility. In the draft paper, Dr. Schonert-Reichl states that these two competencies are based on "the works of CASEL...BC Social Responsibility Performance Standards, and the British Columbia Early Learning Framework" (p. 5). She illustrates the connection between the CASEL competencies of Social Awareness and Relationship Skills and Responsible Decision-Making and the BC categories of Personal Responsibility and Well-Being and Social Responsibility (p. 6). She also outlines research that provides a scientific basis for SEL in the classroom and expands on the effectiveness of SEL when "infused" into the curriculum and continued across multiple years (p. 8). In the report, Dr. Schonert-Reichl notes "that these skills can be taught and that direct instruction and opportunities to practice these skills can occur in classroom/school contexts that are safe, supportive, participatory, and engaging" (p. 5). She emphasizes that successful SEL in schools involves a person-centered focus and classroom environment focus.

The other documents that most closely connect to SEL are those relating to Aboriginal ideologies. An overview of the First Peoples' principles of education are outlined in a Ministry-developed guide entitled "Aboriginal worldviews and perspectives in the classroom" as well as a summary created by the First Nations Education Steering Committee (British Columbia Ministry of Education, 2015a; First Nations Education Steering Committee, 2017). These summaries reveal that SEL is a central tenet of this perspective which views learning as "holistic, reflexive, reflective, experiential, and relational (focused on connectedness, on reciprocal relationships, and a sense of place)" (First Nations Education Steering Committee, 2015). The emphasis on personal, familial, community, spiritual, and environmental well-being underlines the importance of intentionally drawing focus to social and emotional experience and connecting learning in an authentic way.

In 2012, teachers and academics collaborated to apply these underlying principles to develop the new structure and content in their subject-areas. The 2013 report entitled "Exploring curriculum design," summarized key discussion points and excerpted samples generated by the subject-teams elaborating on Big Ideas and Learning Goals for grades 2, 4, 7, and 10 including goals, rationale, skills, and competencies (British Columbia Ministry of Education, 2013b, p. 5). This document points to interesting directions for discussion among subject-groups regarding competencies. For example, the English Language Arts team purposefully considered the overlap between ELA and the Communication competency (p. 5). It is puzzling, however, that no other competencies are mentioned considering the clear applicability of other areas including critical and creative thinking.

This period set the design for the curriculum format and content. The visual layout and elements of the curriculum remain largely the same in the current published drafts. The description in this report for the Cross-Curricular Competencies envision "a description of the competency as it relates to an area of learning, the competency continua, and student samples" (p. 8). The wording of this report restates the intention for 
the competencies to be clearly associated with each subject area and embedded in all classrooms.

The next relevant document to be produced was a draft framework entitled "Defining Cross-Curricular Competencies: Transforming Curriculum and Assessment" (British Columbia Ministry of Education, 2013a). This document provided updated definitions expanding the initial categories to three key competency types made up of eight subcategories: Thinking (Critical and Creative), Personal and Social (Positive Personal and Cultural Identity, Personal Awareness and Responsibility, and Social Awareness and Responsibility), and Communication (Language and Symbols, and Digital Literacy). In line with earlier reports, the competencies are linked to the Goals of Education, the Educated Citizen, and First Peoples' principles of learning (p. 3). While, again, no specific citations are provided, it is inferred that the first two are drawn from the 1989 mandate. Guidance for the redesign is also attributed to "national and international initiatives on essential 21 st century skills" and to academic research in "critical thinking, creative thinking, communication, social and personal responsibility, and Aboriginal perspectives on Cross-Curricular Competencies," again, referring readers to the list of resources on the website (p. 3).

The outline of underlying principles contained in this report revealed a holistic approach to education and the impetus "in a world of growing diversity and challenge" to go beyond traditional subject areas to help students develop "intellectually, personally, and socially" emphasizing contribution to community and life-long learning (p. 3). The authors establish the prominent place of Cross-Curricular Competencies in achieving this goal:

The Cross-Curricular Competencies are the set of intellectual, personal, and social skills that all students need to develop in order to engage in deeper learninglearning that encourages students to look at things from different perspectives, to see the relationships between their learning in different subjects, and to make connections to their previous learning and to their own experiences, as members of their families, communities, and the larger society. (British Columbia Ministry of Education, 2013a, p. 3)

The authors emphasize the connections and the importance of integrating competencies across subjects and grades "in the common purpose of enriching students' learning experience and preparing students for the future" (p. 3). The Ministry also describes the competencies as compatible with the personalized learning model. Manifesting uniquely in each subject area, the competencies consider and promote different views, cultural, and social interpretations and learning contexts for each student (p. 3).

In this version the authors unpack the competencies in a way that reflects the approach suggested by Dr. Schonert-Reichl (2012) in her consultation report. Each competency includes a definition, descriptor, and examples of how teachers can facilitate learning. For example, the Thinking Competency is described as building understanding, habits of mind, and metacognition, which are important to facilitate students' lifelong learning. Within this category, Reflective Thinking includes considering one's own thoughts and learning, drawing connections, extrapolating, and adapting knowledge and skills. Suggestions for teacher facilitation include asking students to connect experiences

Journal of Contemporary Issues in Education, 2017, 12(2), pp. 34-49. 
across different contexts, engaging them in reflection and analysis of how knowledge was acquired, and goal setting (British Columbia Ministry of Education, 2013a, p. 7).

With respect to reporting of student performance in relation to the defined competencies, again it is expressed that the Ministry expects "that reporting on competencies will be considered an important part of communicating student learning" and that they intend to seek additional feedback on this process (p. 2). While there is no comment concerning how students might demonstrate learning, the report makes clear the intention for all students to engage in learning across the competencies and reference is made to addressing the assessment issue as part of the ongoing review of graduation requirements. Most notably regarding assessment, the report confirmed a "process to codevelop resources for teachers, including continua, samples and examples of developing Cross-Curricular Competencies in students' day-to-day learning" (p. 2). Next steps are outlined for the consultation process including gathering additional feedback from teachers and the public and creating support materials including continua and students' samples.

The 2014 "Curriculum Redesign Update" described the process moving forward as proposed with additional development and consultation. This appears to be the first public document in which the shift in terminology for these categories of social and emotional skills moves from "Cross-Curricular Competencies" to "Core Competencies" (British Columbia Ministry of Education, 2014). Again, based on public feedback and additional curriculum-team groupings, the Ministry re-stated the priority to "Ensure Core Competencies are explicit and built into renewed curriculum to support deeper learning and the transfer of key skills and processes to new contexts" (p. 3). The concerns expressed in the feedback continue to centre on the "need for assessment resources to include rubrics, exemplars, self-assessment, and criteria for core and curricular competencies. They also requested clarity on what will be assessed, including revised performance standards and examples of authentic tasks" (p. 7).

In the same year, draft versions of the competency profiles were posted to the BC curriculum website in the areas of Communication, Creative Thinking, and Positive Personal and Cultural Identity with profiles for Critical Thinking, Personal Awareness and Responsibility and Social Responsibility to be added within the next year. A review of these profiles continues to reveal considerable alignment with CASEL competencies. Additionally, these profiles include a series of guiding "I statements" in each competency area that indicate outcomes or "continua" as originally envisioned by the Advisory Group (British Columbia Ministry of Education, 2017a). These statements frame the competencies as learning goals and provide clear objectives to guide planning for teachers and learners.

In 2015, an update for the "BC Education Plan," was released, this time centering on the concept of personalized learning. Connections are drawn between the "foundation skills" of personalized learning and the Core Competencies, though the language does not align with the progression of the wording in previous documents (p. 6). While the defined categories are included, the BC Education Plan advertises that "learners will develop competencies such as: Critical thinking and problem solving; collaboration and leadership; communication and digital literacy; personal and social responsibility; creativity and innovation; global and cultural understanding" (p. 6). This discrepancy seems to foreshadow the sense of disconnect and confusion expressed by teachers that Journal of Contemporary Issues in Education, 2017, 12(2), pp. 34-49. 
continues to underlie the implementation of these new elements in schools (British Columbia Teachers' Federation, 2016).

It is also at this juncture that there is a noticeable change in the language used to describe the reforms within the documents. Previously, the word employed for the overarching objectives that would embed SEL in all subjects was 'Cross-Curricular Competencies.' Here, however, the word 'Core Competencies' is used to distinguish these skills from 'Curricular Competencies', which describe the subject-specific learning objectives. The distinction has a bearing on SEL integration as one might expect the term "core" to reinforce the central role of these affective and cognitive skills. This change may also have contributed to the tendency in future publications for both Core and Curricular to be regularly paired together as "competencies" and to the re-emergence of the primacy of Curricular Competencies.

This shift can also be seen, for example, in the subsequent posting of a "Curriculum Overview" on the BC Ministry website (British Columbia Ministry of Education, 2017b). This text echoes previous documents drawing links to characteristics of the Educated Citizen indicating, "The redesigned curriculum captures these qualities, both implicitly and explicitly, in the core and curricular competencies" (para. 9). Here, the Ministry also outlines the relevance of the competencies to the "Know-DoUnderstand" model underlying the redesign first introduced in the "Enabling Innovation" report. They describe that "competencies" constitute the "Do" element of this model constituting skills that students will be able to use in varying contexts (para. 24). The descriptions appear to focus on the Curricular Competencies while briefly noting the connection to Core Competencies. Interestingly, throughout the overview, Core Competencies are continually mentioned together with the Curricular Competencies in this manner. On the one hand, this may be indicative of the intention of the Ministry that the two be interlaced for teachers and learners. On the other hand, it may also suggest a shift away from the original idea of Core Competencies as the central focus of the curriculum and retreating to the comfort zone of a traditional academic curricular focus. This is perhaps reflective of a need to re-center and bolster the profile of the Core Competencies allowing time to raise teacher's comfort level, and renewing commitment to integrating SEL across the curriculum.

The revised curriculum for grades 10-12 also reveals shifts in language surrounding SEL opportunities. In the Graduation Years Update, for example, the only mention of Core Competencies again draws ties to Curricular Competencies noting that students learn to "think like a scientist in Science, communicate in Mathematics, and become socially responsible in Social Studies" (British Columbia Ministry of Education, $2016 \mathrm{~b}$, p. 10). However, while these outcomes are all very possible, they are not a foregone conclusion and this statement appears to underestimate the knowledge, skill, and intentionality required to develop and nurture SEL.

In 2015, an "Introduction to British Columbia's redesigned curriculum" was published which provided a general summary of the entire process to date (British Columbia Ministry of Education, 2015d). It describes additional consultation and feedback sessions with educators, stakeholders and members of the public. In 2015-2016 80 sessions were held with 27 post-secondary institutions in Canada and US (British Columbia Ministry of Education, 2016a, p. 4). 
Members of the BCTF and other interested professional associations were also asked to provide specific feedback on the redesign drafts to date (British Columbia Teachers' Federation, 2016, p. 14). In response, the BCTF published comments on their website as well as a Discussion Paper which reflected both the positive views and ongoing concerns of their membership. The Federation website states that they ...raised the onus on the Ministry to properly explain the Core Competencies to parents with Ministry staff, and the Federation has also pointed out that the Core Competencies, as they are currently formulated, reflect a narrow set of Eurocentric values that don't acknowledge the diversity of BC classrooms. It is also the Federation's position that collaboration time be made available for teachers to discuss the Core Competencies (British Columbia Teacher's Federation, 2017).

The province officially launched the new curriculum in 2015 with voluntary implementation of the redesigned K-9 programs across $\mathrm{BC}$ with the intention of full implementation in September 2016. Implementation of the revised 10-12 Graduation Years curriculum was delayed by the Ministry due to requests from educators and is now expected to be implemented by 2018/2019 (British Columbia Ministry of Education, 2014). Development of a number of curriculum areas are ongoing and "Educator Updates" continue to be posted to the Ministry website and requests for continued feedback on the various stages are highlighted on the main page. The update from March 2017 reports that consultation and feedback continues to raise the need for additional materials and supports regarding the Core Competencies. Further revisions and supporting materials will be made during the 2017/2018 school year in anticipation of publishing the finalized version of the Core Competencies in the near future (British Columbia Ministry of Education, 2017b).

\section{Competency Based Assessment}

Assessment is the current focus of research and development of the new curriculum movement as evidenced by the recent publications from the Ministry. The Advisory Group on Provincial Assessment agree in their Final Report (British Columbia Ministry of Education, 2013b) that, while focus on the areas of reading, writing, and numeracy should remain, there is also a need to develop assessment of the CrossCurricular Competencies and that they should be included in the "provincial assessment system" (Magnusson \& Frank, 2014, p. 8).

A second report by the Advisory Group on Provincial Assessment was published in 2015 regarding the 10-12 Graduation Years. In this document, the group deviates from the Ministry definitions for Core Competencies instead using the preamble of the BC School Act to identify guiding education goals including literacy, numeracy, curious and critical thinking, a healthy lifestyle, and connection to oneself and society (Magnusson \& Frank, 2015, p. 2). While the reason for this deviation is unclear, connections can be drawn to social and emotional skills contained in the official Ministry competencies. The Advisory Group recommends that assessment in courses such as science and social studies should "focus assessment on related competencies" providing the example that personal identity is closely tied to Social Studies (p. 4). They also emphasize that project-

Journal of Contemporary Issues in Education, 2017, 12(2), pp. 34-49. 
based learning and portfolio formats are more appropriate than provincial examinations (p. 4).

Several stages of consultation generated feedback that raised concerns regarding challenges in assessing areas such as personal awareness and positive identity. In their discussion paper, for example, the BCTF note the ongoing confusion around reporting "such as one member who asked how they would be "translating co-operative learning into a mark" and another who wondered how do you "assess" empathy" (British Columbia Teachers' Federation, 2016, p. 8). Teachers also expressed concerns about lack of guidance and "vague directions leading to a lack of standards" (p. 6).

In 2016, direction on assessment was provided in an Order-in-Council under section 79(3), 85(2), and 168(2) of the School Act entitled "Student Progress Report Order" outlining requirements for reporting in all areas. With respect to SEL areas, reference is made in section $3(\mathrm{~g})$ that all student reports must contain "a description of the student's behaviour, including information on attitudes, work habits, effort and social responsibility" (p. E-86). While no additional detail is provided, the form of this feedback and the tone of the language seem to focus around behaviour intervention and decorum rather than personal growth and development. This directive creates the impetus for teachers to be mindful of these areas during the reporting period.

With respect to the Core Competencies, reporting requirements are raised in Schedule 1 where end-of-year progress reports for K-9 students must include "a student self-assessment on Core Competencies" (s.1(b)(ii), s.2(b)(ii), s.4(b)). For grades 10-12, however, the rule is less clear, stating only that the reporting must receive letter grades and, where appropriate, comments "in relation to expected learning outcomes set out in the curriculum" and "in accordance with the Graduation Transitions Program Guide and DPA Program Guide" (British Columbia Ministry of Education, 2016c, s.5(2), (2.1)).

In March 2017, the Ministry released a draft document entitled "Supporting the Self-Assessment and Reporting of Core Competencies" providing guidance on implementing student self-assessment (British Columbia Ministry of Education, 2017d). This report recommended that, in the initial transition year, students focus on one competency and move towards all competencies in the subsequent years (British Columbia Ministry of Education, 2017c, p. 1). As regards teacher support of selfassessment, the advice is somewhat vague. Ideas centre on drawing attention to and providing feedback on Core Competencies in student learning and suggest "Teachers can explicitly develop the language of Core Competencies with their students through authentic experiences and learning opportunities" (p. 2). Methods such as questioning and conversation are encouraged including sample questions such as "How do you show you were listening thoughtfully?" (p. 2). A list of possible year-end assessments are included ranging from "equations" to "body language" and "wordclouds" (p. 4). However, little is provided in the way of substantive ideas or examples. The concluding comment acknowledges that there are ongoing questions regarding the reporting of Core Competencies and it encourages teachers to continue to look for updates as the process unfolds.

To offer some clarification on the types of activities envisioned by the Ministry, "Illustrations" have been added to the Competency profiles providing samples of student work and classroom activities (British Columbia Ministry of Education, 2015c). While the existing samples are largely representative of the elementary years, these illustrations Journal of Contemporary Issues in Education, 2017, 12(2), pp. 34-49. 
continue to be collected and, together with the guiding "I statements," are key to implementation allowing teachers to understand and innovate in line with stated goals.

\section{Conclusions and Next Steps}

It is clear that there has been a concerted effort on the part of the Ministry to be transparent and to promote the redesign as a living process that is open to and working towards continual improvement. Almost every document listed for use on the curriculum website continues to be watermarked as a draft, perhaps to indicate that feedback, suggestions, and consultation is ongoing and welcome.

To increase transparency and understanding for all stakeholders unfamiliar with SEL learning in particular, more detailed disclosure and specificity with respect to source materials would be useful. The Ministry should consider publishing author names and specific research citations for separate parts of the development process simultaneous with materials and information available to the public. As in academia, citations and source material create a roadmap for the ideas, exploration, and conclusions behind policy decision-making. This practice has been improved in some of the most recent publications including the guidelines for competency assessment which lists contributors and cites specific references (British Columbia Ministry of Education, 2017d). Transparency breeds trust and it is incumbent upon the Ministry not only to outline the overall initiative but also to identify for interested parties the authorship, advisors, researchers, consulting stakeholders, and the inspiration materials particularly for the new ideas.

At this juncture, in order to include SEL in an effective way, it would be beneficial for the Ministry and school systems to refocus efforts on the original premise around which the curriculum was born - the Core Competencies. The planners would advance the agenda by creating the subject-specific "competency links" and capitalizing on the natural relationship between the competencies and academic subjects. Reverting to more familiar language and traditional curriculum and diluting this forward thinking program to serve expediency and placate concerns will defeat the purpose and future benefits to students.

It is understandable that $\mathrm{BC}$ teachers express concern. While SEL has an increasingly prominent profile in educational circles in Canada, much of the research and work with respect to program implementation has occurred in the USA. Further, while select teacher education programs have recently begun to explore SEL opportunities (e.g. University of British Columbia, 2016), a majority of BC classroom teachers have had limited exposure to SEL theory and benefits and so are naturally apprehensive regarding incorporating content into their lessons. This is another area where publishing the underlying research, including the technical paper on SEL commissioned by the Ministry, would prove useful by allowing teachers to understand the 'big picture' of SEL theory and integration.

The BCTF Discussion Paper outlines a number of the concerns that continue to be raised by teachers during implementation. The major theme was that a "gap between 'vision' and 'reality' underpins many of the tensions between what are seen to be positive aspects of the curriculum and how the curriculum has been redesigned and is being implemented" (p. 3). This is also reflected in the disparity between the initial idea to Journal of Contemporary Issues in Education, 2017, 12(2), pp. 34-49. 
focus on Core Competencies as the root of the curriculum, relating each subject back to those "essential" skills (British Columbia Ministry of Education, 2012, p. 9). The paper calls for updated resources, in-service time, and clarification of the general process (British Columbia Teachers' Federation, 2016). However, these supports are also required specifically regarding Core Competencies. Without skill-based professional development in these areas, how can teachers engage students in self-assessment by "intentionally noticing, naming, and connecting the Core Competencies to their learning" (British Columbia Ministry of Education, 2017c, p. 2)?

While illustrations and samples continue to be compiled, the reporting guidelines for Core Competencies indicate that teachers should look to relate the Core Competencies to the Curricular Competencies when the original idea was to focus on Core Competencies and connect content and subject matter to those underlying goals. Again, this difference may impact attention to these core skills as originally envisioned by the Advisory Group and widely supported in public and educator feedback.

Self-assessment of the Core Competencies is a valid and important goal. Students should be reflecting and experiencing personal growth in the identified areas, being fully aware of their own improvement in listening, dispute resolution, empathy, and consciously forming and embracing their personal and cultural identities. However, although the curriculum changes will encourage an appreciation and attention for selfassessment, the realities of the transition to self-assessment must still be considered. The current reality is that between the busy school system and the professional lives of teachers, student self-assessments may get lost in the hustle and bustle, particularly at the middle and high school levels.

This reality is reflected in the fact that, while the debate endures in education research as to the merits and challenges of letter grades, the Ministry continues to mandate the use of letter grading in reporting in grades 4-12, even with the 2016 update (British Columbia Ministry of Education, 2016c, s.2(a), s.4(a), s.5(a)). Focus of teachers and students will continue to be drawn to indicators that dictate what "counts" when it comes to learning outcomes. In order to follow the steps first taken in 2001 by elevating "social responsibility" to the level of importance of numeracy and literacy in the Performance Standards, the Core Competencies must be assessed in a way that conveys equal importance and the central position of these skills to the new curriculum direction.

As seen from the outset of the public consultation process, there is consensus on the importance of Core Competencies to students' future success. However, there is real risk of losing sight of this larger mission in the face of the significant challenge of meaningful implementation and assessment. Future research might examine approaches to the evaluation or demonstration of competencies that are both efficacious and realistic and also explore ways in which self-assessment can be meaningfully managed or combined with other types of reporting to legitimize Core Competency development in the eyes of students, parents, educators and post-secondary stakeholders.

Revisiting the original vision of education planners of making purposeful connections between academic subjects and Core Competencies would facilitate the nurturing of social and emotional skills integrating practices, language, and mindful consideration into the everyday curriculum. Progress might also be realized by investing in teacher education, professional development, and support for educators that facilitate the development of SEL knowledge and competencies. Helping teachers to explore Core Journal of Contemporary Issues in Education, 2017, 12(2), pp. 34-49. 
Competency integration in learning goals, Big Ideas, and every day classroom tasks will support the big-picture model presented in the new curriculum. This may also serve to reorient educators and stakeholders to the SEL mission and help to address the gap in understanding and application that currently exists in an otherwise positive, and progressive movement in education for the $21^{\text {st }}$ century.

\section{References}

Ananiadou, K., \& Claro, M. (2009). 21st century skills and competences for new millennium learners in OECD countries. OECD Publishing. Retrieved from http://www.oecd-ilibrary.org/education/21st-century-skills-and-competences-fornew-millennium-learners-in-oecd-countries_218525261154

Bridgeland, J., Bruce, M., \& Hariharan, A. (2013). The missing piece: A national teacher survey on how social and emotional learning can empower children and transform schools. Retrieved from http://files.eric.ed.gov/fulltext/ED558068.pdf

British Columbia Ministry of Education. (2001). Social responsibility: A framework. Vancouver, BC. Retrieved from http://www2.gov.bc.ca/assets/gov/education/administration/kindergarten-to-grade12/performance-standards/social-responsibility/sintro.pdf

British Columbia Ministry of Education. (2012). Enabling innovation transforming curriculum and assessment enabling innovation. Vancouver, BC. Retrieved from https://www.bced.gov.bc.ca/irp/docs/ca_transformation.pdf

British Columbia Ministry of Education. (2013a). Defining cross-curricular competencies - transforming curriculum and assessment. Vancouver, BC. Retrieved from https://www.bced.gov.bc.ca/irp/docs/def_xcurr_comps.pdf

British Columbia Ministry of Education. (2013b). Exploring curriculum design: Transforming curriculum and assessment. Vancouver, BC. Retrieved from http://www.bced.gov.bc.ca/irp/docs/exp_curr_design.pdf

British Columbia Ministry of Education. (2014). Curriculum redesign update. Vancouver, BC. Retrieved from https://curriculum.gov.bc.ca/sites/curriculum.gov.bc.ca/files/pdf/Curriculum Redesign Update Winter.pdf

British Columbia Ministry of Education. (2015a). Aboriginal worldviews and perspectives in the classroom. Victoria, BC. Retrieved from http://www2.gov.bc.ca/assets/gov/education/administration/kindergarten-to-grade12/aboriginal-education/awp_moving_forward.pdf

British Columbia Ministry of Education. (2015b). B.C.'s Redesigned Curriculum. Retrieved October 8, 2017, from http://www2.gov.bc.ca/gov/content/educationtraining/k-12/teach/curriculum/redesigned-curriculum

British Columbia Ministry of Education. (2015c). Core Competencies. Retrieved May 6, 2017, from https://curriculum.gov.bc.ca/competencies

British Columbia Ministry of Education. (2015d). Introduction to British Columbia's redesigned curriculum. Vancouver, British Columbia. Retrieved from https://curriculum.gov.bc.ca/sites/curriculum.gov.bc.ca/files/pdf/curriculum_intro.pd $\mathrm{f}$

British Columbia Ministry of Education. (2016a). Curriculum parent guide. Vancouver, Journal of Contemporary Issues in Education, 2017, 12(2), pp. 34-49. 
BC. Retrieved from http://www2.gov.bc.ca/assets/gov/education/kindergarten-tograde-12/support/curriculum-parent-guide.pdf

British Columbia Ministry of Education. (2016b). Educator update: Graduation years, grades 10-12. Vancouver, BC. Retrieved from https://curriculum.gov.bc.ca/sites/curriculum.gov.bc.ca/files/pdf/updates/201701educator-update-graduation-assessment.pdf

British Columbia Ministry of Education. (2016c). Student progress report order. Vancouver, BC. Retrieved from http://www2.gov.bc.ca/assets/gov/education/administration/legislationpolicy/legislation/schoollaw/e/m191_94.pdf

British Columbia Ministry of Education. (2017a). Core competencies: Building student success - BC's new curriculum. Retrieved April 15, 2017, from https://curriculum.gov.bc.ca/competencies

British Columbia Ministry of Education. (2017b). Curriculum Overview: Building Student Success BC's New Curriculum. Retrieved April 22, 2017, from https://curriculum.gov.bc.ca/curriculum/overview

British Columbia Ministry of Education. (2017c). New Curriculum. Retrieved October 8, 2017, from https://curriculum.gov.bc.ca/curriculum-updates

British Columbia Ministry of Education. (2017d). Supporting the self-assessment and reporting of core competencies. Vancouver, BC. Retrieved from https://curriculum.gov.bc.ca/sites/curriculum.gov.bc.ca/files/pdf/supporting-selfassessment.pdf

British Columbia Teacher's Federation. (2017). BC Education Change. Retrieved April 1, 2017, from http://bctf.ca/IssuesInEducation.aspx?id=38331\#core

British Columbia Teachers' Federation. (2016). Discussion paper: Diverse perspectives of BCTF members on the redesigned BC curriculum. Vancouver, BC. Retrieved from http://www.bctf.ca/uploadedFiles/Public/Issues/Curriculum/CurriculumFeedbackRe port.pdf

Brummet, A. J. (2013). Mandate for the school system (No. OIC 1280/89). School Act, 1996, s 169 (3). Vancouver, BC: British Columbia Ministry of Education. Retrieved from http://www2.gov.bc.ca/assets/gov/education/administration/legislationpolicy/legislation/schoollaw/d/oic_128089.pdf

Collaborative for Academic Social and Emotional Learning. (2015). 2015 CASEL guide: Effective social and emotional learning programs-Middle and High School edition. Chicago, IL. Retrieved from http://secondaryguide.casel.org/casel-secondaryguide.pdf

Collaborative for Academic Social and Emotional Learning. (2016). Core SEL Competencies. Retrieved December 9, 2016, from http://www.casel.org/corecompetencies/

Durlak, J. A., Weissberg, R. P., Dymicki, A. B., Taylor, R. D., \& Schellinger, K. B. (2011). The impact of enhancing students' social and emotional learning: A metaanalysis of school-based universal interventions. Child Development, 82(1), 405432. http://doi.org/10.1111/j.1467-8624.2010.01564.x

Elias, M. J., Zins, J. E., Graczyk, P. A., \& Weissberg, R. P. (2003). Implementation, sustainability, and scaling up of social-emotional and academic innovations in Journal of Contemporary Issues in Education, 2017, 12(2), pp. 34-49. 
public schools. School Psychology Review, 32(3), 303-319. Retrieved from http://www.effectiveservices.org/downloads/Implementation_Sustainability_and_ Scaling Up of Social-

Emotional_and_Academic_Innovations_in_Public_Schools.pdf

First Nations Education Steering Committee. (2015). First Peoples principles of learning. Vancouver, BC: First Nations Education Steering Committee. Retrieved from http://www.fnesc.ca/wp/wp-content/uploads/2015/09/PUB-LFP-POSTERPrinciples-of-Learning-First-Peoples-poster-11x17.pdf

First Nations Education Steering Committee. (2017). Learning First Peoples classroom resources. Retrieved April 23, 2017, from http://www.fnesc.ca/learningfirstpeoples/

Magnusson, K., \& Frank, B. (2014). The advisory group on provincial assessment: Final report. Vancouver, BC. Retrieved from https://curriculum.gov.bc.ca/sites/curriculum.gov.bc.ca/files/pdf/agpa_report.pdf Magnusson, K., \& Frank, B. (2015). Advisory Group on Provincial Assessment: The Graduation Learning Years. Vancouver, BC. Retrieved from https://curriculum.gov.bc.ca/sites/curriculum.gov.bc.ca/files/pdf/agpa-finalreport.pdf

National Education Association. (2010). Preparing 21st century students for a global society: An educator's guide to the "Four Cs." Washington, DC. Retrieved from http://www.nea.org/assets/docs/A-Guide-to-Four-Cs.pdf

National Research Council. (2012). Education for life and work: Developing transferable knowledge and skills in the 21st century. Washington, D.C.: National Academies Press. http://doi.org/10.17226/13398

Partnership for 21 st Century Learning. (2009). Framework for 21 st century learning. Washington, DC. Retrieved from http://www.p21.org/storage/documents/docs/P21_framework_0816.pdf

Schonert-Reichl, K. A. (2012). Social and emotional learning (SEL) in British Columbia K-12 curriculum: Competencies of personal responsibility and well-being, and social responsibility. Vancouver, BC. Retrieved from https://sd48seatosky.files.wordpress.com/2014/03/bc-moe-paper-on-personalresponsibility-and-social-responsibility.pdf

University of British Columbia. (2016). Social and emotional learning (SEL) in the UBC teacher education program. Retrieved October 7, 2017, from http://teach.educ.ubc.ca/social-and-emotional-learning-in-the-ubc-teachereducation-program/

Winans, A. (2012). Cultivating critical emotional literacy: Cognitive and contemplative approaches to engaging difference. College English, 75(2), 150-170. Retrieved from http://www.jstor.org.ezproxy.library.uvic.ca/stable/24238137

Zins, J. E., \& Elias, M. J. (2006). Social and emotional learning. In K. M. George Bear (Ed.), Children's Needs III (pp. 1-14). Michigan: National Association of School Psychologists. Retrieved from https://www.thomstecher.com/Content/Frontend/docs/CASEL SEL and Academics.pdf

Journal of Contemporary Issues in Education, 2017, 12(2), pp. 34-49. 